\title{
Efficacy of teaching creative thinking skills: A comparison of multiple creativity
}

\section{assessments}

By: Anna Perry and Elena Karpova

Perry, A., \& Karpova, E. (2017). Efficacy of teaching creative thinking skills: A comparison of multiple assessments. Thinking Skills and Creativity Journal, 24, 118-126.

https://doi.org/10.1016/j.tsc.2017.02.017

Made available courtesy of Elsevier: http://dx.doi.org/10.1016/i.tsc.2017.02.017

(c) (1) () $\Theta$

cc)

Attribution-NonCommercial-NoDerivatives 4.0 International License.

\section{Abstract:}

The purpose of this study was tri-fold: (1) to evaluate the efficacy of a creative thinking course using three different assessments; (2) to analyze changes in creativity as a result of the training for individual participants; and (3) to investigate reasons for individual decreases in creativity after the training. Data was collected at the beginning and the end of a creative thinking course at a large land-grant Midwestern university. After the course, students had the most significant increase in belief in their own creative abilities, followed by an increase in attitude toward risk-taking, and creative thinking evaluated by experts. While as a group, participants had significantly increased their creative abilities, several of them demonstrated a decrease in creative abilities after the course. A statistical phenomenon, regression to the mean, was employed to explain why some participants demonstrated lower creative thinking after completing the course.

Keywords: Creative thinking | Training | Risk taking | Regression to the mean | Torrance Test of Creative Thinking

\section{Article:}

\section{Introduction}

Creative thinking produces tangible objects and ideas that are (1) novel, original, unexpected and (2) appropriate, useful, and adaptive concerning task constraints (Mumford, 2003, Runco and Jaeger, 2012, Sternberg and Kaufman, 2010). Creative thinking is essential for the long-term success of individuals, companies, industries, and nations (Ford \& Gioia, 2000). Kim (2011) reported that, for the first time in decades, creativity has been declining in the USA across all age groups. This decline in creativity is evident in children becoming less imaginative, verbally expressive, passionate, able to synthesize diverse information, motivated to elaborate ideas and details, capable of capturing the essence of problems, intellectually curious, and open to new experiences (Kim, 2011). Potential consequences of this trend are far-reaching because 
creativity is vital in every aspect of our lives (Runco, 2007).

Many researchers have reported that creativity can be increased as a result of training. Most extant studies used only a single assessment to evaluate the efficacy of creativity training (e.g., Karpova, Marcketti, \& Barker, 2011; McIntyre, Hite, \& Rickard, 2003). Few studies have investigated effects of training on creativity using multiple assessments. This is despite the fact that scholars agree that creativity, as a multifaceted phenomenon, should be evaluated from various perspectives, using different types of assessments (Reiter-Palmon, Robinso-Morral, Kaufman, \& Santo, 2012; Treffinger, Young, Selby, \& Shepardson, 2002). In addition, researchers are unsure whether efficacy of creativity training evaluated by different assessments might be the same or not. It has been noted that it is important to investigate effectiveness of creativity training using multiple assessments (Bertrand, 2005; Scott, Leritz, \& Mumford, 2004).

Further, studies that examine efficacy of creativity training typically present results for the entire sample and do not discuss how the creative thinking of individual participants had changed after training. Karpova et al. (2011) reported that even though an overall sample's creative thinking had increased after a series of exercises, some individuals had demonstrated no change or a decrease in creative thinking. This issue has not received attention in the literature, even though it is important to understand how and why an individual participant's creativity might be affected after taking a creative thinking course. The objectives of this study were: (1) to evaluate the efficacy of a creative thinking course using different assessments; (2) to analyze changes in creativity as a result of the training for individual participants; and (3) to investigate reasons for individual decreases in creativity after the training.

\subsection{Theoretical background}

Growth mindset theory (Dweck, 2006) was used as a theoretical foundation in this study. The theory suggests that a person's skills and abilities can be cultivated through teaching and learning (Dweck, 2006). According to this theory, the human brain is a muscle that can be developed as a result of training. Growth mindset theory supports a foundation for training programs that aim to develop creativity through learning and practicing creative thinking strategies and through transforming information and experiences from training into new knowledge and skills. Based on the theory, creativity can be improved through training (Fryer, 1996, Rose and Lin, 1984).

\subsection{Creativity assessment}

Creativity is a complex, multifaceted phenomenon and should be evaluated from various perspectives (Treffinger et al., 2002). In this study, creativity was evaluated using three distinct assessments: (1) expert-assessment of creative thinking; (2) belief in their own creative abilities, and (3) a personal characteristic associated with creativity.

The Torrance Test of Creative Thinking (TTCT) was chosen as an expert-based assessment of creative thinking. It is the most widely used expert-assessment of creativity (Davis, 1997). Specifically, the figural format of the test was used in our study. TTCT test takers are asked to finish three activities (picture construction, picture completion, and filling in lines/circles) in 30 min with 10 min per activity (Torrance, 2008). Participant work is scored on multiple creative dimensions by trained experts. The creative dimensions are combined into a Creativity Index, which reflects a participant's overall level of creative thinking (Torrance, 2008). 
An assessment of their own beliefs about creative abilities is a simple way to assess one's creativity (Kaufman, Plucker, \& Baer, 2008). The assessment measures one's belief in his or her competencies in producing novel and appropriate work and abilities to utilize those competencies to create final products (Lemons, 2005). Another way to evaluate creative thinking skills is to assess a personal characteristic that is a pre-cursor to creative attitudes and behaviors (Kaufman et al., 2008). Attitude toward risk-taking, which refers to a decision maker's tendency to take or to avoid risk when given a choice (Sitkin \& Pablo, 1992), was chosen in this study. Empirical studies have shown that risk-taking is one of the most important traits in determining one's creativity (Lubart, 1994, Russ, 1993). Even though many other personal characteristics (e.g., openness to experience or flexibility) have been linked to creativity, the limitations of this study did not allow the inclusion of any more research variables for examination.

\subsection{Efficacy of creativity training}

Extant research supports that creative thinking can be increased as a result of training. For example, participants demonstrated higher TTCT scores after completing a series of creative exercises (Karpova et al., 2011; Fleith, Renzulli, \& Westberg, 2002), a short-term meditation session (Ding, Tang, Tang, \& Posner, 2014), a two-day innovation boot camp (West, Tateishi, Wright, \& Fonoimoana, 2012), and after being taught by well-trained creativity teachers (Assareh, Ghahremani, Abaspour, \& Abadi, 2013). Meta-analyses of previous studies have also indicated that participants' TTCT scores can be enhanced by training (Hollingsworth, 1991, Rose and Lin, 1984, Scope, 1998).

Researchers have also reported that after creativity training, people tended to view themselves as more creative individuals, which resulted in a higher belief in their own creative abilities (Birdi, 2005; Gilbert, Prenshaw, \& Ivy, 1992; Karwowski \& Soszynski, 2008) as well as a willingness to take a greater risk with their ideas (Dewett \& Gruys, 2007). Based on the growth mindset theory and previous research, we proposed that as a result of training, participants had higher creativity, as measured by all three types of assessments:

H1: Creative thinking measured by TTCT is higher after training than before the training.

H2: Belief in their own creative abilities are higher after training than before the training.

H3: Attitude toward risk-taking is higher after training than before the training. 


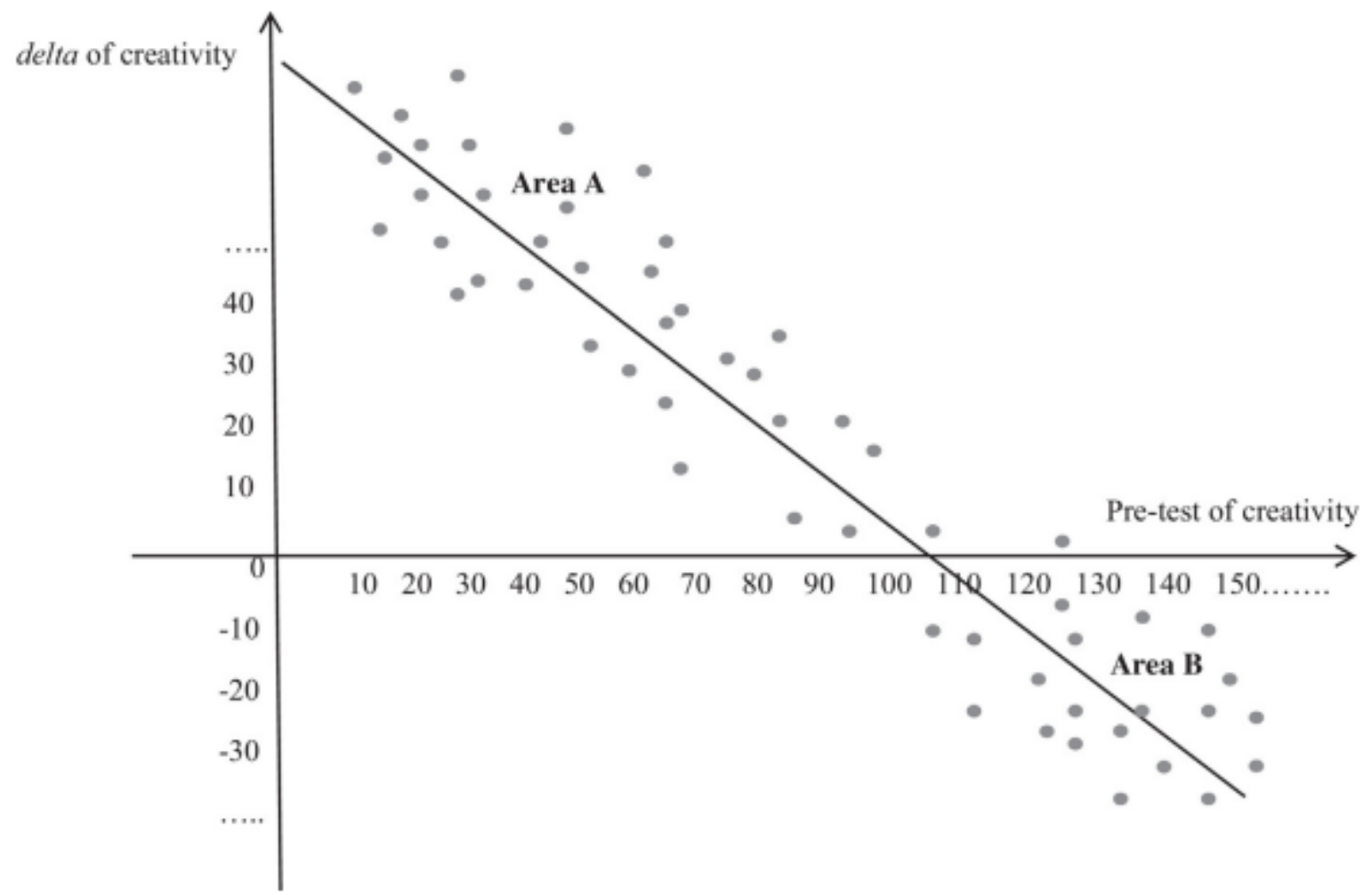

Fig 1. Test of regression to the mean (RTM).

\subsection{Creativity training effects on individual participants}

Although researchers have reported that, as a group, participants tend to increase in creativity after training (e.g., Craft, 2000, Karwowski and Soszynski, 2008), it was noted that some individuals demonstrated a decrease in creativity (Karpova et al., 2011). It is unknown why some participants might demonstrate a decrease in creativity after training. To better understand the efficacy of teaching creative thinking, it is important to discuss and examine possible reasons for an individual's decrease in creativity after training.

First, the fact that some participants might not demonstrate an increase in creativity after training might be attributed to limitations of the instrument used for the assessment. The range of data that can be collected is limited by the instrument's ceiling and floor, the maximum and the minimum values (Vogt, 2005). A ceiling effect occurs when data cannot be collected at a value higher than the highest number of the instrument's range, and a floor effect occurs when data cannot be collected at a value lower than the lowest number of the instrument's range. The ceiling effect might explain why some participant's creativity did not increase after training. For example, if a participant had the maximum creativity score before training, this participant would have no chance to receive an even higher score due to the instrument limit, and therefore, this participant would demonstrate a decline or no change in his/her score.

Second, a statistical phenomenon known as regression to the mean (RTM) can be used to explain why some participants might demonstrate a decline in creativity after training. RTM occurs when a repeated measurement is taken on the same subjects when collecting data: relatively high (relatively low) values taken at the first time of measurement tend to decrease 
(increase) to the true mean in subsequent measures (Barnett, Van der Pols, \& Dobson, 2005). RTM happens because data is collected with a random error (e.g., random measurement error, or random fluctuations in a subject) (Barnett et al., 2005). For example, people might feel more or less creative at different times due to various emotional and/or physical conditions, such as being tired or distracted/focused, feeling sad or happy. Because the data is rarely collected without random error, RTM is a common phenomenon (Barnett et al., 2005).

To test the RTM effect, the current study examined how creativity scores measured before the training are related to the delta of creativity, which is the difference between creativity measured after the training (post-test) and creativity measured before the training (pre-test). Given the existing instruments, pre-test and post-test creativity scores are always positive. The delta of creativity values (post-test minus pre-test) can be negative (in the case when a participant demonstrates a decrease in creativity after the training) or positive (in the case when a participant demonstrates an increase in creativity after the training). If there is a significant negative relationship between pre-test creativity and the delta of creativity (Fig. 1), then:

1. participants with relatively low creativity scores in the pre-test are likely to have a positive delta (area A), which indicates that these participants demonstrated an increase in creativity in the post-test; and

2. participants with relatively high creativity scores in the pre-test are likely to have a negative delta (area B), which reveals that these participants demonstrated a decrease in creativity in the post-test.

In other words, the RTM effect is proven by a negative relationship between creativity measured before the training and the delta of creativity.

Typically, to assess the efficacy of creativity training, a repeated measurement method is used to collect data on the same subjects before and after the training (e.g., Dewett and Gruys, 2007, Fleith et al., 2002, Karpova et al., 2011, Karwowski and Soszynski, 2008). As discussed above, a repeated measurement might result in a RTM effect (Barnett et al., 2005). In the current study, repeated measurements before (pre-test) and after the training (post-test) were used to collect data using TTCT, belief in their own creative abilities scale, and attitude toward risk-taking scale. To test for the RTM effect, the following hypotheses were proposed:

H4: For TTCT, pre-test score is negatively related to the creativity delta, the difference between post-test and pre-test score.

H5: For belief in their own creative abilities, pre-test score is negatively related to the beliefs delta, the difference between post-test and pre-test score.

H6: For attitude toward risk-taking, pre-test score is negatively related to the risk-taking delta, the difference between post-test and pre-test score.

\section{Method}

\subsection{Instruments}

The Torrance Test of Creative Thinking (TTCT) was used to measure participant 
creativity by experts. To measure belief in their own creative abilities and attitude toward risk-taking, a survey was used. The survey also included questions to collect participant demographics: age, gender, race, academic major, and academic classification (year in college).

Torrance Test of Creative Thinking (TTCT). The figural format of TTCT was used to measure participant creative thinking as assessed by trained, independent experts (Torrance, 1999). The test's two forms, A and B, were used for the pre-test and the post-test, respectively. The Creativity Index based on participant age, a composite score of the overall level of a participant's creativity, was used in the analysis. The Creativity Index is calculated based on the participant's grade (number of years in school) and age. Because all of the participants were college students, their academic level was counted as the 13th grade. Therefore, it was deemed more appropriate to use the Creativity Index based on age. In addition, the authors ran data for both Creativity Indexes, and the results were almost identical.

Belief in their own creative abilities. Belief in their own creative abilities scale was used to assess participant perception of their own creative attitudes and behaviors. Eleven items were adapted from George and Zhou (2001) and Tierney and Farmer (2002). Example items were: "I am a creative individual", "I am good at coming up with unique ideas", and "I use my creative abilities when faced with challenges." The questions used a seven-point Likert-type scale with the anchors "strongly disagree" (1) and "strongly agree" (7).

Attitude toward risk-taking. The attitude toward risk-taking scale was used to assess a participant's inclination to take risks with his or her ideas. Four items were adapted from a risk-taking propensity scale and a general willingness to take risks scale (MacCrimmon and Wehrung, 1990, Sitkin and Pablo, 1992). Example items were: "I take risks with my ideas" and "I am comfortable taking risks." All items were measured with a 7-point Likert-type scale ranging from "strongly disagree" (1) to "strongly agree" (7).

\subsection{Procedure}

The research sample was composed of students enrolled in an undergraduate creative thinking course at a large land-grant Midwestern university. The course focused on learning and practicing creative thinking concepts and strategies to help students to: view things from different perspectives, identify unique opportunities, generate multiple unique ideas to solve problems, and evaluate ideas. The course included 24 creative mini-projects, which were completed individually, and three full-scale projects that were completed in teams of two-three students. For example, one mini-project, the Square Challenge, asked students to take 15 photos of unusual square objects that met the following criteria: in each photo, the square object takes the same amount of space and placement, regardless of the object's actual size. This project helped students to see ordinary things in new and different ways. One team-based project, Packaging Challenge, asked students to create new shoe packaging concepts to minimize packaging cost and waste (about 11 billion shoe boxes are produced and discarded every year worldwide).

This study was approved by an Institutional Review Board. The data was collected at the beginning and at the end of a sixteen-week semester. During the first and last weeks of the semester, students completed the TTCT test and a survey during a class period. TTCT booklets were administered according to the guidelines from the publisher of the test and then mailed to the publisher for scoring by trained experts (Torrance, 2008). The data from both TTCTs and surveys were entered into a spreadsheet for statistical analyses. 


\subsection{Participants}

All 47 students enrolled in the course were invited and agreed to participate in the study. Forty-five students participated in the data collection at the beginning of the semester, and 42 students - at the end of the semester. The paired data (collected both at the beginning and at the end of the course from a student) sample size was 40. Participants' age ranged from 18 to 23, with an average age of 20.49 years $(\mathrm{SD}=1.27)$. The majority of the participants were female students $(\mathrm{n}=44 ; 97.8 \%)$, White or Caucasian $(\mathrm{n}=38 ; 84.4 \%)$, and majored in apparel merchandizing and design $(n=28 ; 62.2 \%)$ and event management $(n=12 ; 26.7 \%)$. All participants were undergraduate students.

Data analysis was completed using SPSS 20 and SAS 9.3. First, descriptive statistics were computed. Next, factor analysis was used for data reduction and to assess construct validity. To determine the efficacy of a creative thinking course, a general linear model (GLM) of repeated measures was used to compare means at the beginning and at the end of the course (Hypotheses H1, H2, H3). Simple regression was used to examine regression to the mean and to test Hypotheses H4, H5, and H6.

\section{Results and discussion}

\subsection{Factor analysis}

A Principal Component Analysis with Promax rotation was conducted to reduce the survey data and extract factors (Fabrigar, Wegener, MacCallum, \& Strahan, 1999). Eigenvalues above 1.0 were used to determine the number of factors. Two factors were extracted from the total of 15 survey items, with eigenvalues of 8.81 (belief in their own creative abilities) and 1.55 (attitude toward risk-taking). One item was deleted because it loaded on both factors with loadings of .59 and .37 , respectively. To have distinct factors, each item's loading in one factor should be higher than .50 , and, at the same time, the loadings in the other factors should be lower than .30 (Kline, 1998). Out of the 14 remaining items, ten items $(M=49.38, S D=9.96)$ generated the first factor, belief in their own creative abilities. This factor explained $58.7 \%$ of the variance in the total 14 items. Four items $(\mathrm{M}=17.42, \mathrm{SD}=4.56)$ generated the second factor, attitude toward risk-taking, and explained $10.33 \%$ of the variance in the total 14 items. Cronbach's alpha for the belief in their own creative abilities scale was .95, and for the attitude toward risk-taking scale was .80 .

\subsection{Correlations}

Table 1 provides correlation coefficients between the three research variables. All variables measured in the pre-test (labeled with 1) were highly correlated with the same variables measured in the post-test (labeled with 2). Pre-test TTCT was correlated with post-test TTCT (r $=.50, \mathrm{p}=.001$ ). Pre-test belief in their own creative abilities (BOCA) was correlated with post-test belief in their own creative abilities $(r=.72, p<.001)$. Pre-test attitude toward risk-taking (ATRT) was correlated with post-test attitude toward risk-taking $(\mathrm{r}=.55, \mathrm{p}<.001)$. 
Table 1. Correlations among the three research variables

\begin{tabular}{|l|c|c|c|c|c|c|}
\hline & 1 TTCT1 & 2 TTCT2 & 3 BOCA1 & 4 BOCA2 & 5 ATRT1 & 6 ATRT2 \\
\hline 1. TTCT1 & 1 & & & & & \\
\hline 2. TTCT2 & $.50^{* *}$ & 1 & & & & \\
\hline 3. BOCA1 & -.08 & .04 & 1 & & & \\
\hline 4. BOCA2 & -.06 & .003 & $.72^{* *}$ & 1 & & \\
\hline 5. ATRT1 & -.11 & .06 & $.70^{* *}$ & $.54^{* *}$ & 1 & \\
\hline 6. ATRT2 & .14 & .002 & $.34^{*}$ & $.69^{* *}$ & $.55^{* *}$ & 1 \\
\hline
\end{tabular}

$* \mathrm{p}=.05$.

$* * \mathrm{p}=.001$. TTCT $=$ Torrance Tests of Creative Thinking; BOCA $=$ belief in their own creative abilities; ATRT - attitude toward risk-tasking

Table 2. Research variables at the beginning and at the end of the creative thinking course.

\begin{tabular}{|l|l|l|l|l|l|l|l|l|l|l|}
\hline & & $\mathrm{N}$ & $\begin{array}{l}\text { Pre-tes } \\
\mathrm{t} \text { mean }\end{array}$ & $\mathrm{SD}$ & $\begin{array}{l}\text { Post-test } \\
\text { mean }\end{array}$ & $\mathrm{SD}$ & $\mathrm{df}$ & $\mathrm{F}$ & $\begin{array}{l}\text { Sign. } \\
(\mathrm{p})\end{array}$ & $\begin{array}{l}\text { Partial } \\
\eta^{2}\end{array}$ \\
\hline H1 & TTCT & 40 & 107.83 & 16.21 & 114.48 & 14.65 & $(1,39)$ & $7.40^{*}$ & .010 & .160 \\
\hline H2 & BOCA & 40 & 48.7 & 9.76 & 54.18 & 8.55 & $(1,39)$ & $25.22^{* *}$ & .0001 & .393 \\
\hline H3 & ATRT & 40 & 17.03 & 4.43 & 19.77 & 5.19 & $(1,39)$ & $14.58^{* *}$ & .0001 & .272 \\
\hline
\end{tabular}

Table 3. Pre-test descriptive statistics and number of students with no increase after the training

\begin{tabular}{|l|l|l|l|l|l|l|l|l|}
\hline & Mean 1 & SD 1 & Min 1 & Max 1 & $\begin{array}{l}\text { Decreased } \\
\text { score (n) }\end{array}$ & $\%$ & $\begin{array}{l}\text { No change in } \\
\text { the score (n) }\end{array}$ & $\%$ \\
\hline TTCT & 107.83 & 16.21 & 76 & 147 & 15 & 37.5 & 1 & 2.5 \\
\hline BOCA & 48.7 & 9.76 & 31 & 67 & 5 & 12.5 & 1 & 2.5 \\
\hline ATRT & 17.03 & 4.43 & 8 & 26 & 4 & 10.3 & 6 & 15.4 \\
\hline
\end{tabular}

The two self-reported variables were significantly correlated: the pre-test belief in their own creative abilities was correlated with the pre-test $(r=.70, p<.001)$ and the post-test attitude toward risk-taking $(\mathrm{r}=.34, \mathrm{p}=.04)$. The post-test belief in their own creative abilities was 
correlated with the pre-test $(\mathrm{r}=.54, \mathrm{p}<.001)$ and the post-test attitude toward risk-taking $(\mathrm{r}=$ $.69, \mathrm{p}<.001)$. Because the two variables were both self-reported and administered at the same time, belief in their own creative abilities and attitude toward risk-taking were expected to be closely related (Chang, Van Witteloostuijn, \& Eden, 2010).

The two self-reported variables, belief in their own creative abilities and attitude toward risk-taking, were not correlated with the creative thinking measured by TTCT for both, the pre-test and the post-test data sets. The finding was consistent with previous research that reported lack of correlation between creative thinking assessed by experts (measured by TTCT) and self-assessed creativity (e.g., Furnham, Batey, Booth, Patel, \& Lozinskaya, 2011; Lew et al., 2013). The result might indicate that the two constructs measured different dimensions of the complex creativity phenomenon. In this case, using different assessments might be recommended when assessing effectiveness of a creativity training. Another possible explanation for the lack of relationship between expert-assessed and self-reported creativity might be that participants were subjective in assessing their own creative abilities, whereas the experts, who evaluated creativity based on a comparison of all student's projects, might be more objective (Priest, 2006).

\subsection{Effectiveness of creativity training}

The general linear model (GLM) repeated measures analysis of variance was used to analyze the effect of training on student creativity measured by the three assessments. GLM is an analysis of variance typically used when the same measurement is made twice on each participant. Creative thinking, belief in their own creative abilities, and attitude toward risk-taking were the dependent variables. The within-subjects factors were creative thinking, belief in their own creative abilities, and attitude toward risk-taking. These within-subjects factors had 2 levels as there are repetitions (e.g., pre-test and post-test) and the levels were within-subjects independent variables. There were no between subject variables. Hypotheses 1 , 2 , and 3 were supported (Table 2). After the creative thinking course, students had a significantly higher creativity score as assessed by experts and measured by TTCT $(\mathrm{H} 1: \mathrm{F}(1,39)=7.4, \mathrm{p}=$ $.01)$. Further, participants reported significantly higher belief in their own creative abilities (H2: $\mathrm{F}(1,39)=25.22, \mathrm{p}<.0001$ and attitude toward risk-taking $(\mathrm{H} 3: \mathrm{F}(1,39)=14.58, \mathrm{p}=.0001)$ at the end of the course than at the beginning of the course.

Cohen (1988) suggests that a small effect size, $\eta 2$, (from .02 to .13) can only be detected through a very careful study, whereas a large effect size (higher than .26) is big and consistent enough to be seen 'with the naked eye', and a medium effect can be found between a small effect and a large effect (greater than .13 but smaller than .26). Therefore, there is a medium effect size with 16 percent of the variation in TTCT, and there are two large effect sizes with 39.3 percent of the variation in the belief in their own creative abilities and 27.2 percent of the variation in the attitude toward risk-taking, which can be attributed to the efficacy of the creative thinking course (Table 2).

\subsection{Decreased creativity after training}

Even though participants' creativity and risk-taking for the whole sample showed a significant increase after the training (Table 2), some students had demonstrated a decline (or no change) in their creative thinking (as measured by TTCT), belief in their creative abilities, and risk-taking at the end of the course. Out of the total 40 participants, the number of participants 
who had a decline in their scores after the course were as follows: fifteen students $(37.5 \%)$ for their TTCT; five students (12.5\%) for their belief in their own creative abilities; and four students $(10.3 \%)$ for their attitude toward risk-taking (Table 3$)$. In addition, the number of students who had no change in their scores after the course were as follows: one student $(2.5 \%)$ for their TTCT; one student $(2.5 \%)$ for their belief in their own creative abilities, and six students (15.4\%) for their attitude toward risk-taking (Table 3). Analysis of the individual student data revealed that the students, who demonstrated a decline in creativity, were not the same students. In other words, a student might have recorded an increase in their TTCT and risk-taking but a decrease in their belief in their own creative abilities.

To check the ceiling effect, as one of the possible reasons for a decline in creativity after the training, maximum and minimum values for all three variables at the pre-test were analyzed (Table 3). The possible maximum value for the Creativity Index (TTCT assessment) was 150. A seven-point scale was used to measure the belief in their own creative abilities (10 items) and for the attitude toward risk-taking (4 items). Hence, the maximum values for these two constructs were 70 and 28, respectively. None of the participants had the maximum values on any of these three constructs at the pre-test. The highest scores for the TTCT, belief in their own creative abilities, and attitude toward risk-taking at the pre-test were 147, 67, and 26, respectively. None of the participants were at the actual ceiling at the pre-test and so had a chance to further increase creativity-related assessments, as measured by the three research constructs. Therefore, the ceiling effect was not detected in this study. In other words, the ceiling effect was not the reason for a decline in the three research constructs after the training, because none of the participants gained the maximum scores on any of the assessments at the pre-test.

A possible floor effect was also examined. The minimum value for each scale (e.g., TTCT, belief in their own creative abilities, and attitude toward risk-taking) is 1 . Therefore, for each construct, the lowest possible score was 1 . None of the participants had the minimum value on each of the three constructs at the pre-test: the lowest scores for the TTCT, belief in their own creative abilities, and attitude toward risk-taking at the pre-test were 76,31 , and 8 , respectively. Therefore, the floor effect was not present in our study. The analysis of the ceiling and floor effects was important to rule them out as a possible explanation for a decline in the creativity scores after the training (Pakhale et al., 2012).

Another possible reason for a decline in the creativity scores after the training might be regression to the mean (RTM). Hypotheses 4, 5, and 6, were supported, confirming the RTM effect for all three research constructs (Table 4). The TTCT pre-test scores were negatively related to the TTCT deltas $\left(\mathrm{H} 4: \mathrm{F}_{(1,38)}=18.54, \mathrm{t}=-4.31, \mathrm{p}<.0001\right)$. The pre-test scores of the belief in their own creative abilities were negatively related to the deltas $\left(\mathrm{H} 5: \mathrm{F}_{(1,48)}=13.96, \mathrm{t}=\right.$ $-3.74, \mathrm{p}=.0006)$. The pre-test scores of the attitude toward risk-taking were negatively related to the deltas $\left(\mathrm{H} 6: \mathrm{F}_{(1,37)}=4.95, \mathrm{t}=-2.22, \mathrm{p}=.03\right)$.

The results indicated that high pre-test scores were related to negative deltas, which means that the post-test scores were lower than the pre-test scores (see Fig. 1, area B). This finding confirms that participants with relatively high creativity assessments' scores before the training tended to demonstrate a decline in the scores of these assessments after the training. Further, low pre-test scores were related to positive deltas, which means that the post-test scores were lower than the pre-test scores (see Fig. 1, area A). This finding confirms that participants with relatively low creativity assessments' scores before the training tend to demonstrate an increase in the scores of these assessments after the training. In other words, the negative relationships between the pre-test variables and the associated delta values prove the RTM 
effects for the three research constructs: the TTCT, belief in their own creative abilities, and attitude toward risk-taking. When the RTM effect exists, participants with higher scores at the pre-test tend to have a decrease in scores at the post-test, regardless of the effectiveness of a training program (Barnett et al., 2005).

Table 4 Regression to the mean (RTM) effects for the three research constructs

\begin{tabular}{|l|l|l|l|l|l|l|l|l|}
\hline & Variable & $\mathrm{N}$ & $\mathrm{df}$ & $\mathrm{F}$ & $\mathrm{p}$ & $\mathrm{R}^{2}$ & $\mathrm{t}$ & $\mathrm{p}$ \\
\hline H3 & TTCT1 $\rightarrow$ Delta TTCT & 40 & $(1,38)$ & 18.54 & $.0001^{* *}$ & .33 & -4.31 & $.0001^{* *}$ \\
\hline H4 & BOCA1 $\rightarrow$ Delta BOCA & 40 & $(1,38)$ & 13.96 & $.0006^{* *}$ & .27 & -3.74 & $.0006^{* *}$ \\
\hline H5 & ATRT1 $\rightarrow$ Delta ATRT & 39 & $(1,37)$ & 4.95 & $.03^{*}$ & .12 & -2.22 & $.03 *$ \\
\hline
\end{tabular}

$* \mathrm{p}=.05$.

$* * p=.001$

\section{Conclusions}

\subsection{Conclusions and implications}

The results of the study indicate that the creative thinking course was effective in increasing participant creativity measured by two different assessments: expert-assessed, using the TTCT, and self-assessed, using the belief in their own creative abilities scale. In addition, the training significantly increased participant attitudes toward risk-taking, which is an important predictor of creativity (Lubart, 1994, Russ, 1993). Student scores on all three assessments were higher after the training in comparison with the measurements taken before the training. This was despite the fact that both self-reported variables, belief in their own creative abilities and attitude toward risk-taking, were found to be not correlated with the creative thinking evaluated by experts.

Participants demonstrated an ability in generating a greater number of unique ideas after completing the creative thinking course than at the beginning of the course (as measured by the TTCT). Participants also believed that they were more open to take risks with their ideas and more confident about their creative abilities at the end of the course than at the beginning of the course. These findings have important implications for educators and organizations that want to increase their students' or employees' ability to generate new ideas, encourage them to step out of their comfort zone, and increase their self-confidence in their own creative abilities. This study demonstrated that various creative attributes can be increased as a result of one training.

The creative thinking course in this study was found to increase participant creative thinking, belief in their own creative abilities, and attitude toward risk-taking. However, the degree of the increase was different. This result contradicts Bertrand's (2005) conclusion that there is no difference in the effect sizes between the TTCT and other creativity assessments. In the current study, the large effect size (.393) was found for the belief in their own creative abilities, followed by another large effect size (.272) reported for the attitude toward risk-taking. The medium effect size (.16) was found for creative thinking, as measured by the TTCT assessment. These findings indicate that the creative thinking course was the most effective in 
increasing belief in their own creative abilities, followed by the risk-taking attitude. The course was less effective in increasing creative thinking assessed by independent experts. These findings indicate that assessed efficacy of creativity training might depend on the type of assessments employed: how the creativity construct is conceptualized and measured. Researchers should be cautious in choosing assessments to evaluate the efficacy of teaching and learning creative skills.

Although, as a whole sample, participants had significantly increased their scores in creative thinking, belief in their creative ability, and risk-taking after the training, some of them showed a decline for these three research constructs at the end of the course. To explain the decline in creativity after the training, the study confirmed the regression to the mean (RTM) effects, which were found for all of the three research variables. The RTM effect shows that participants with high creativity scores before the training tend to have a decrease in the creativity scores after the training. In other words, a decline in the creativity scores for some participants after the training can be attributed to regression to the mean, rather than the effectiveness of the creative thinking course. This research, for the first time, attempted to answer the question why some participants might demonstrate a decrease in creativity and risk-taking attitude after training, when the overall sample indicates a significant increase in the measured constructs. This knowledge will help researchers in evaluating efficacy of teaching creativity for individual participants.

\subsection{Limitations and suggestions for future research}

In the current study, the participants were predominantly young female students, whose age ranged from 18 to 23 years. Most of them were White, or Caucasian, and majored in apparel or event management. Even though there is no evidence that the efficacy of creativity training depends on gender or age (Kaufman and Baer, 2008, Kim and Pierce, 2013), the results of the study might not be generalizable to other populations.

It is unknown how much variance in the increased creativity and risk-taking attitude scores after the training can be attributed to the regression to the mean vs. to the efficacy of the creative thinking course. When regression to the mean exists, participants with relatively low scores in the pre-test tend to demonstrate a higher score in the post-test, even without training, and vice versa (Barnett et al., 2005). To account for the regression to the mean effect and discern the pure effect of training on participant creativity, a control group is needed when using repeated measures as an evaluation method of training efficacy. The real training effect on creativity would be equal to the change of creativity in the experiment group (the training effect + the effect of regression to the mean) less the change of creativity in the control group (the effect of the regression to the mean). This method would help to distinguish between the real effects of training on creativity vs. the regression to the mean effect due to repeated measures.

Future research should examine other reasons, besides the regression to the mean, to explain a decrease in the creativity and risk-taking attitude after the training. Among possible reasons to consider are: (a) the amount of effort participants invested in completing the survey and TTCT activities; (b) the amount of stress participants experienced when completing these activities. For example, some participants might have put less effort when completing the assessments at the post-test than they did at the pre-test, which would influence their creativity scores as measured by TTCT. Further, the post-test was conducted at the end of the semester. Students are likely to be more tired and stressed out during the last week of the semester with many deadlines and final exams. This might have a significant effect on the overall attitude 
toward completion of the survey and, especially, for the TTCT assessment when participants have to produce a large number of original ideas in a limited time period.

The present study demonstrated that training can increase participants' creativity, both self-reported and expert-evaluated, as well as attitude toward risk-taking. However, no study has yet examined how an ability to generate original ideas is related to real life achievements. Therefore, a study about creativity and real life achievements should be considered. In addition, no study has investigated whether a creativity training effect is long-lasting. Hence, a longitudinal study of creativity training effectiveness should be considered. Future research might use a larger and more diverse sample.

\section{References}

Assareh, A., Ghahremani, A. A., Abaspour, H., \& Abadi, A. L. M. (2013). The study on the impact of teachers' creativity training on improvement of creativity in students and their insights on teacher. Journal of Educational and Management Studies, 3(4), 278-284.

Barnett, A. G., Van der Pols, J. C., \& Dobson, A. J. (2005). Regression to the mean: What it is and how to deal with it. International Journal of Epidemiology, 34, 215-220.

Bertrand, J. R. (2005). Can individual creativity be enhanced by training? (Doctoral dissertation). Retrieved from ProQuest Dissertations and Theses database. (UMI No. 3196767).

Birdi, K. S. (2005). No idea? Evaluating the effectiveness of creativity training. Journal of European Industrial Training, 29(2), 102-111. http://dx.doi.org/10.1108/03090590510585073

Chang, S. J., Van Witteloostuijn, A., \& Eden, L. (2010). From the editors: Common method variance in international business research. Journal of International Business Studies, 41, $178-184$.

Cohen, J. (1988). Statistical power analysis for the behavioral sciences (2nd ed.). Lawrence Erlbaum Associates: New Jersey.

Craft, A. (2000). Creativity across the primary curriculum: Framing and developing practice. London: Routledge.

Davis, G. A. (1997). Identifying creative students and measuring creativity. In N. Colangelo, \& G. A. Davis (Eds.), Handbook of gifted education (pp. 269-281). Needham Heights, MA: Viacom.

Dewett, T., \& Gruys, M. L. (2007). Advancing the case for creativity through graduate business education. Thinking Skills and Creativity, 2(2), 85-95.

Ding, X., Tang, Y.-Y., Tang, R., \& Posner, M. (2014). Improving creativity performance by short-term meditation. Behavioral and Brain Functions, 10(9), 1-8.

Dweck, C. (2006). Mindset: The new psychology of success. New York: Ballantine Books.

Fabrigar, R. L., Wegener, T. D., MacCallum, C. R., \& Strahan, J. E. (1999). Evaluating the use of exploratory factor analysis in psychological research. Psychological Methods, 4(3), 272-299.

Fleith, D. S., Renzulli, J. S., \& Westberg, K. L. (2002). Effects of a creativity training program on divergent thinking abilities and self-concept in monolingual and bilingual classrooms. Creativity Research Journal, 14(3-4), 373-386.

Ford, C., \& Gioia, D. (2000). Factors influencing creativity in the domain of managerial decision making. Journal of Management, 26(4), 705-732.

Fryer, M. (1996). Creative teaching and learning. London: Paul Chapman Publishing Ltd. 
Furnham, A., Batey, M., Booth, T. W., Patel, V., \& Lozinskaya, D. (2011). Individual difference predictors of creativity in Art and Science students. Thinking Skills and Creativity, 6, 114-121.

George, J., \& Zhou, J. (2001). When openness to experience and conscientiousness are related to creative behavior: An interactional approach. Journal of Applied Psychology, 86, 513-524.

Gilbert, F. W., Prenshaw, P. J., \& Ivy, T. T. (1992). Creativity through education: A process for enhancing students' self-perceptions. Journal of Marketing Education, 14, 35-40.

Hollingsworth, M. A. (1991). A meta-analysis of existing creativity training research: An evaluation of program effectiveness and possible confounding variables (Unpublished master's thesis). Winston-Salem, NC: Wake Forest University.

Karpova, E., Marcketti, S. B., \& Barker, J. (2011). The efficacy of teaching creativity: Assessment of student creative thinking before and after exercises. Clothing and Textiles Research Journal, 29(1), 52-66. http://dx.doi.org/10.1177/0887302X11400065

Karwowski, M., \& Soszynski, M. (2008). How to develop creative imagination? Assumptions, aims and effectiveness of role play training in creativity (RPTC). Thinking Skills and Creativity, 3, 163-171.

Kaufman, J. C., \& Baer, J. (2008). Gender differences in creativity. Journal of Creative Behavior, 42(2), 75-105. http://dx.doi.org/10.1002/j.2162-6057.2008.tb01289.x

Kaufman, J. C., Plucker, J. A., \& Baer, J. (2008). Essentials of creativity assessment. New Jersey: John Wiley \& Sons.

Kim, K. H. (2011). The creativity crisis: The decrease in creative thinking scores on the Torrance Tests of creative thinking. Creativity Research Journal, 23(4), 285-295.

Kim, K. H., \& Pierce, R. A. (2013). Creativity and Age. In E. G. Carayannis (Ed.), Encyclopedia of creativity, invention innovation and entrepreneurship (pp. 364-368). New York, NY: Springer.

Kline, R. B. (1998). Principles and practice of structural equation modeling. New York: Guilford Press.

Lemons, G. K. (2005). A qualitative investigation of college students' creative self-efficacy (Doctoral dissertation). Retrieved from ProQuest Dissertations and Theses database (UMI No. 3202456).

Lew, K., Park, J.-H., Lee, K.-C., \& Kang, S. M. (2013). The relationship among creativity thinking ability, creative personality and creative product. Advanced Science and Technology Letters, 36, 58-62. Retrieved from http://onlinepresent.org/proceedings/vol36 2013/14.pdf

Lubart, T. I. (1994). Creativity. In R. J. Sternberg (Ed.), Thinking and problem solving. Handbook of perception and cognition (2nd ed., pp. 289-332). San Diego, CA: Academic Press.

MacCrimmon, K. R., \& Wehrung, D. A. (1990). Characteristics of risk taking executives. Management Science, 36, 422-435.

McIntyre, F. S., Hite, R. E., \& Rickard, M. K. (2003). Individual characteristics and creativity in the marketing classroom: Exploratory insights. Journal of Marketing Education, 25, $143-149$.

Mumford, M. D. (2003). Where have we been, where are we going? Taking stock in creativity research. Creativity Research Journal, 15(2-3), 107-120.

Pakhale, S., Wood-Dauphinee, S., Spahija, A., Collet, J.-P., Maltais, F., Bernard, S., Baltzan, M., 
Rouleau, M., \& Bourbeau, J. (2012). Validation of a new questionnaire with generic and disease-specific qualities: The McGill COPD Quality of Life Questionnaire. Canadian Respiratory Journal, 19(6), 367-372.

Priest, T. (2006). Self-evaluation, creativity, and musical achievement. Psychology of Music, 34, 47-61.

Reiter-Palmon, R., Robinso-Morral, E. J., Kaufman, J. C., \& Santo, J. B. (2012). Evaluation of self-perceptions of creativity: Is it a useful criterion? Creativity Research Journal, 24(2-3), 107-114.

Rose, L. H., \& Lin, H.-T. (1984). A meta-analysis of long-term creativity training programs. The Journal of Creative Behavior, 18(1), 11-22.

Runco, M. A. (2007). To understand is to create: An epistemological perspective on human nature and personal creativity. In R. Richards (Ed.), Everyday creativity and new views of human nature: Psychological, social, and spiritual perspectives (pp. 91-107). Washington, DC: American Psychological Association.

Runco, M. A., \& Jaeger, G. J. (2012). The standard definition of creativity. Creativity Research Journal, 24(1), 92-96.

Russ, S. W. (1993). Affect and creativity: The role of affect and play in the creative process. Hillsdale, NJ: Lawrence Erlbaum Associates.

Scope, E. E. (1998). A meta-analysis of research on creativity: The effects of instructional variables (Unpublished doctoral dissertation). Bronx, NY: Fordham University.

Scott, G., Leritz, L. E., \& Mumford, M. D. (2004). The effectiveness of creativity training: A quantitative review. Creativity Research Journal, 16(4), 361-388.

Sitkin, S. B., \& Pablo, A. L. (1992). Reconceptualizing the determinants of risk behavior. Academy of Management Review, 17(1), 9-38.

Sternberg, R., \& Kaufman, J. (2010). Constraints on creativity. In J. Kaufman, \& R. Sternberg (Eds.), The Cambridge handbook of creativity (pp. 467-482). New York, NY: Cambridge University Press.

Tierney, P., \& Farmer, S. M. (2002). Creative self-efficacy: Its potential antecedents and relationship to creative performance. The Academy of Management Journal, 45(6), $1137-1148$

Torrance, P. E. (1999). The Torrance tests of creative thinking: Norms and technical manual. Scholastic testing Services: Bensenville, IL.

Torrance, E. P. (2008). Torrance Tests of Creative Thinking: Norms-technical manual, verbal forms A and B. Bensenville, IL: Scholastic Testing Service.

Treffinger, D., Young, G., Selby, E., \& Shepardson, C. (2002). Assessing creativity: A guide for educators. Storrs, CT: The National Research Center on the Gifted and Talented.

West, R. E., Tateishi, I., Wright, G. A., \& Fonoimoana, M. (2012). Innovation 101: Promoting undergraduate innovation through a two-day boot camp. Creativity Research Journal, 24(2-3), 243-251.

Vogt, W. P. (2005). Dictionary of statistics \& methodology: A nontechnical guide for the social sciences. Thousand Oaks, CA: Sage Publications. 